\title{
Mobile Photography and Social Networks: Production, Consumption, Socialization and Copyright Practices Among University Students*
}

\author{
Jacob Bañuelos Capistrán \\ Tecnológico de Monterrey-Mexico City Campus, Mexico
}

\begin{abstract}
The following study shall analyse results of an exploration into production, consumption, socialization, privacy and copyright practices among Mexican university students who take photography through mobile devices in social networks. This work focuses on an analysis of how digital natives carry out image capture, how much time is spent on this activity and what types of images are consumed in different types of social networks. It also examines what type of images are captured and what is done with these images in social networks. The study is applied to a specific sample of 93 university students who have full access to mobile devices, applications and social networks in their daily lives. It provides information as to their behavior within a changing techno-social scene which sees the emergence of new mobile devices, specialized applications and social networks dedicated to photography along with other nascent forms and styles of digital production and socialization. This shall be compared to a previous study carried out in 2010 .
\end{abstract}

Keywords: mobile photography, production, consumption, socialization, privacy, copyright, photographic social networks

\section{Introduction}

Within a contemporary context, the practice of photography as carried out through mobile decives is exposed to constant and significant changes. This gives rise to new forms of production, consumption and socialization of the photographic image along with a confrontation of copyright problems.

As such, the study at hand aims to explore the photographic practices undertaken by a sample of 93 Mexican university students aged 19-25. These students are habitual users of smartphones and study Mass Communication, Digital Media, Digital Marketing, Animation and Digital Art.

Our 2010 study on photographic competencies among digital natives was a first approach at understanding practices of production, consumption, socialization, knowledge of copyright issues, cultural practices and photographic compentencies among a sample that was similar in size to that of our work at hand. The 2010 study is entitled Photography 2.0: Competencies and Cultural Practices in Digital Natives (Bañuelos, 2011).

\footnotetext{
* Acknowledgements: I wish to thank the young people studying Communication Sciences and Animation - Digital Art who took the Photography and Digital Imagery course 2014-15 at the Tecnológico de Monterrey, Mexico City Campus for willingly contributing their answers to this study.

Jacob Bañuelos Capistrán, Ph.D., Professor, Department of Communication and Digital Art, Tecnológico de Monterrey-Mexico City Campus.
} 
The work at hand continues to explore these practices of production, consumption, socialization and knowledge of copyright. However, the focus now turns to better understanding these practices in an environment of mobile phones and in the use of social networks employed by young people.

Both studies allow a glimpse and a comparison of significant changes in terms of use of photography due to greater and more habitual use of smartphones with Internet access, the appearance of mobile applications dedicated to photography and the emergence of visual social networks such as Instagram. These were either non-existent or just beginning to appear in 2010. As such, some meaningful comparisons between both studies can be emphasized.

How are production, consumption, socialization and copyright practices in terms of mobile photography and social networks carried out among Mexican university-aged young people who study communication? This is the pivotal question that guides the study at hand.

\section{Context}

The use of mobile phones and smartphones with Internet access has increased significantly in Mexico during the past years. The Mexican Internet Association [Asociación Mexicana de Internet] (AMIPCI, 2015) reveals habits of Internet consumption for 2015:

- The population connected to the Internet in Mexico has reached $51 \%$ penetration for potential users (from 6 years of age). The total figure has reached 53.9 millones users with $5.3 \%$ rate of growth compared to the previous study.

- There is a $37 \%$ penetration for people aged $19-34.50 \%$ are men and $50 \%$ are women.

- $27 \%$ of these users live in the central part of the country. Users in areas of least density (South and Southwest) represent $6 \%$ and $5 \%$, respectively. $15 \%$ of users are located in the Northwest, while in the rest of the country, the Internaut population ranges from $11 \%$ to $13 \%$.

- There is an increase in exposure time to Internet, with an average of 6 hours and 11 minutes daily. This represents 24 minutes more than the 2014 figure of 5 hours and 36 minutes.

- As in 2014, the vast majority connect to Internet at home (84\%) followed by work (42\%). In the case of schools, there is no longer a reduction trend as in previous years. It has now overtaken last year's rate with $36 \%$ (34\% in 2013).

- Connections via purchased WiFi signal showed a growth of $14 \%$ (66\% in $2014,80 \%$ in 2015$)$

- The smartphones segment grew from $49 \%$ to $58 \%$, overtaking desktop computers (54\%).

- $87 \%$ of smartphone users navigate the Internet. $79 \%$ use information searches and $77 \%$ receive and send emails. Users check files, read news and download multimedia materials (music, photos, videos) in proportions close to $50 \%$.

- $82 \%$ of internauts have downloaded and installed apps on their intelligent celphones.

- For the first time in history, social networks are on the cutting edge with $85 \%$ among internauts (in 2014 main use was email), followed by information searches (78\%) and email mail, now occupying third place with $73 \%$.

- $93 \%$ of Mexican internauts have at least one account in some type of social network.

The sample of students analysed in the study at hand is well represented in the figures in context of Mexican society as per the qualities of the AMPCI (2015) study. This is due to the fact that the AMPCI (2015) study explores $47 \%$ of the population representing the upper and upper-middle classes - the very segments to which our sample belongs. 


\section{Literature Review}

We are now witnessing an onslaught of studies related to consumption of mobile photography, social networks and Internet. Research in these areas has been growing exponentially in the academic world and on an international stage.

As such, we may find works of reference that frame a global reflection upon practices of Internet usage and a wide range of applied, exploratory studies that tackle the practices of mobile phones and photography in social networks. These analyse the phenomena from diverse disciplinary perspectives and focus on the study of technological, participative, identity-causing, cultural patterning, aesthetic, ethnographic and behavioral aspects.

The corpus of prior studies is vast. Thus, we shall cite only some of the most useful studies to guide and frame the work at hand. These references serve as state of the art guideposts, framing what has been studied on the topic to present day.

As mentioned earlier, in 2010 we carried out a similar study entitled Photography 2.0: Competencies and Cultural Practices. Our study was focused on practices of production, organization of files, socialization, privacy and copyright (Bañuelos, 2011). The methodology was identical and the sample of students was nearly identical to the work at hand. This study is useful in comparing some relevant aspects of the state of the art and mobile photographic culture from 5 years ago till present day.

Some of the theoretical referrents used for the 2010 study are still quite pertinent for understanding a general framework of use of telephony and mobile communication. These are Castells (2007) with his Comunicación móvil y sociedad (Mobile Communication and Society, 2007), Comunicación y poder (Communication and Power, 2009), and his Sociedad Red. La era de la información, economía, sociedad y cultura (Network Society: The information age, economy, society and culture, 2006), and his more recent reflection upon the power of networks and role of mobiles in social movements and democracy entitled Democracy in the age of the Internet (Castells, 2011).

Also more recently we find the study by Van Dijck (2008), entitled Digital photography: Communication, Identity, Memory, in which the transformation in individual and social practices brought on by digitization and photographic instantenity is analysed along with its impact on the creation of identity and virtual memory. We also find the work of Thompson (2005) who analyses effects relating to image and interaction in context of the War on Irak in his The New Visiblity.

From Nov, Naaman, and Ye (2008), we find Community photo sharing: Motivational and structural antecedents, a study in which a model of digital photographic exchange is proposed. This is based on the great fields of individual motivations and structural communitary relationships. Counts and Fellheimer (2004) explore the growth of photographic exchange upon daily events through Flippr, an application created for mobile phones which is similar to Snapfish. Van House and Davis (2005) in The Social Life of cameraphone images examine the use of images through Mobile Media Metadata 2, a system of photographic exchange via celphone in terms of memory, socialization, self-presentation, personal expression, and functional and documentary uses.

Sarvas and Lehmuskallio (2008), in their Snapshot media: "Kodak culture" in the 21st Century, formulate the term snapshot media, and conclude that the photographic processes of capture, production and digital socialization exclude the older generations and those groups unfamiliar with digital technologies. Miller-Ott, 
Kelly, and Duran (2012) study the rules of satisfaction in love relationships through photographs shared via mobiles.

The London School of Economics and Political Science (LSE, 2013), from its Department of Media and Communications has recently published a useful compendium of studies undertaken from 2002 to 2012 entitled Mobile Visual References. Yet another interesting compendium is that of Gaby David who has put together a set of studies on the selfie in The selfie research network (David, 2014).

Other contemporary studies on photographic consumption and socialization through mobile phones are characterized by their work in joining diverse perspectives in global contexts and their greater focus on the use of social networks. Examples are Hand (2012) who deals with the concept of ubiquitous photography; Sarvas and Frohlich (2011) on snapshot uses in social networks and changes in domestic photography and Araya, Breindl, and Houghton (2011), and Nov, Naaman, and Ye (2010), on communitary participation and socialization online from a multidimensional perspective.

Studies of greater regional scope are well represented, Yan (2015) who coordinates an encyclopedia of studies upon behaviors with smartphones, and the works of Hjorth $(2012,2010,2009)$, on photographic practices with mobile phones, artistic practices, photoshopping and the cultural impact of mobile technology (larissahjorth.net/list-of-publications/).

From Lev Manovich and Nadav Hochman $(2013,2012,2009)$ (Software Studies Initiative) ${ }^{1}$, two exemplary research projects entitled Phototrails (http://phototrails.net/ 2013) and Selfiecity (http://selfiecity.net/\#, 2014) are highlighted where millions of photos and selfies are analysed in social networks such as Instagram through metadata analyses (Big visual data y "fragmented images") to establish aesthetic and cultural patterns in photographs among users.

\section{Theoretical Framework}

In order to undertake an analysis of practices in mobile photography and social networks for the study at hand, we revisit two basic conceptual categories. These allow for the analysis of production, consumption, socialization, privacy and copyright tendencies for our sample.

The first category - the kodakers - has been formulated by Chalfen (1987) in Snapshot versions of life. This is his base study upon technological competencies and cultural practices of amateur photographers in which he coins the term "Kodak Culture". Users in this photographic culture are called "kodakers", and they use photography to tell a type of story where aspects of daily and private life are realized while emotional ties to family and friends are inforced.

The second conceptual category, the snapers, has been formulated by Miller and Edwards (2012, 2007), in their Give and take: A study of consumer photo-sharing culture and practice. They bring forth a comparative analysis between traditional users or "digital migrants" from the Kodak Culture and the new producer-diffusers of digital photography in social networks, or "snaprs", who are characterized by their high-level technological competencies in the use of digital photography, social networks such as Flickr, and beginning to socialize notions of privacy in social networks. The snaprs are also characterized by their near instantaneous sharing of images in photographic networks.

\footnotetext{
1 The Graduate Center, City University of New York, California Institute for Telecommunication and Information. http://www.gc.cuny.edu/Home.
} 


\section{Methodology}

Our research here stems from an empirical study which explores technological competencies and cultural practices among 92 university students of whom 64 are women and 29 are men. They are students at a private higher education institution in Mexico City and belong to upper and upper-middle classes.

The work at hand attempts to address the question of how Mexican university students are using mobile photography and social networks. Other secondary questions explored will address which devices are used and how much time is invested in each, the types of applications students use to take photos, social networks being used, motivating factors for taking photos, topics being photographed, the use of photos and student knowledge about privacy and copyright issues in social networks.

In determining the sample, it was important that students were taking classes of Photography and Digital Imagery and registered in degree programs of Communication Sciences, Digital Art-Animation or Marketing and Digital Media.

Another necessary factor, as with our prior study (Bañuelos, 2011) is that our students in the sample were "digital natives" (Prensky, 2001; Palfrey, 2008), born in the nineties and ranging from 19 and 25 years of age. Yet other conditions were that these students had access to Internet, that they were users of some social network and had a digital camera and used a mobile phone with a camera. It was not considered a pre-requisite that students knew how to use a digital reflex camera or that they already had an account in a specialized photography site such Flickr.com

An anonymous questionnaire was applied with 39 multiple choice questions through a digital system that sent the questions to students' emails. The questionnaire was left open for one month to allow all students to answer. Questions were formulated around six main categories in terms of mobile photograhy use: production, consumption, socialization, privacy, copyright and photography social networks. The work at hand is a second approach to these topics and will undoubtedly be the object of future studies.

\section{Analysis and Interpretation of Results}

We shall present and analyse questionnaire results based on the following categories: production, consumption, socialization, privacy, and copyright. In keeping with these results, we shall reflect upon student use of mobile photography and social networks.

\section{Production}

In this section, we put together results related to capture of photographs via smartphones, devices, operating system, and expenditure on mobile consumption. We also explore if students give importance to quality of the device's camera, frequency of shots taken, topics, use of applications and values of photographic quality. We have found that $62 \%$ of our sample use a smartphone compared to $29 \%$ who use a celphone without Internet access. It is quite significant that the majority of the sample use a smartphone and that $63 \%$ use the Apple operating system (iPhone) compared to $35 \%$ who use Android. $35 \%$ of the sample report spending between 500 and 800 pesos (approximately 40 dollars) monthly in maintaining mobile services, a high cost for students without income. $88 \%$ of the students report interest in celular camera quality, and this may explain why the vast majority use IPhones.

In terms of snapsnot frequency, the majority or $72 \%$ take photos daily or every other day whereas $20 \%$ take photos once a week. Here we find a great difference between our previous study (Bañuelos, 2011), in 
which a once-a-week snapshot frequency was reported among $38 \%$ of respondents and $29 \%$ of respondents reported taking snapshots three times per week. In contrast, $92 \%$ of our current sample take photos at least once a week, and this shows a marked increase.

In terms of motives for taking photos, the most relevant, leading response at $34 \%$ is "sharing my experience", followed by "expressing my emotions" and "documenting reality", virtually tied at $23.6 \%$. Contrasted to this is the motive of "making friends", which leads at $49 \%$ as the least relevant reason reported for taking photos.

Interestingly, however, when we turn to photographed topics or themes, "friends" is the most significant (9.13 points out of a total of 13), followed by "travel" ( 8.78 points) and landscapes ( 8.68 points) and at a third level of relevance stand "objects around me" (8.08 points), "self portrait" (7.71), "festivities" (7.69) and "family" (7.44). The least photographed topic reported is "the nude" (2.66 puntos). Once again as in our previous study (Bañuelos, 2011), "friends" leads the list (50\%), followed by "travel" (45.7\%) in terms of photographed topics.

$74 \%$ of the students polled report to pay particular attention to values of photographic quality such as focus, composition, lighting, color, contrast, volumen, scale, brightness, blur and movement. The most carefully watched value is that of "composition" with $42 \%$ giving it priority as greatest relevance, followed by "focus" (21\%) and "lighting" (15.6\%). The least relevant value is that of "scale", which no respondent claims as relevant and reaches a mere 3.27 points out of $10.81 \%$ of respondents say they are interested in their photos having "a definite photographic aesthetic".

$65 \%$ use a photo application via mobile and mainly employ it for "retouch" or "editing" (58\%), followed by a "social network" application (50\%), and "snapshot and modification" (35\%). The most widely used application is Instagram (72\%), followed by Snapchat (31\%) and Snapseed (11\%). In our 2010 study (Bañuelos, 2011), Instagram was not yet on the scene of mobile applications, as it did not make its first appearance until October 6 of that same year. Current use of Instagram in the study at hand, then, is highly significant.

\section{Consumption}

In this section, we shall put together the results of an exploration into the social networks students are using in order to view and make comments and we shall attempt to understand which types of photos are seen with greater frequency. Findings show that Instagram is the most used social network in visualizing photographs (49\%), followed by Facebook (15\%) and Pinterest (13.9\%); the least used networks for visualizing photos are Flickr (5.3\%), Twitter (3.23\%) and 500pixels (3.23\%). This provides significant information as Flickr and 500pixels are highly specialized in photography. In the case of Twitter, despite being a highly visual network, it is being used very little by our sample for photo visualization.

An average of $32 \%$ dedicate between 15 and 20 minutes daily to the activity of seeing photos in a social network, while $27 \%$ report spending 30 minutes to one hour on this activity. This means that nearly $60 \%$ of our sample spend between 15 minutes and one hour viewing photos on a social network while $21 \%$ spend one to three hours daily on this activity.

As with the previous study (Bañuelos, 2011), the most viewed topics are having to do with "friends" (44\%), "famous people" (18\%) and "landscapes" (7.5\%). What is least seen or consumed is "national news" $(0.0 \%$ as option with the most relevance), "politics" $(1.0 \%)$ and "citizen movements" $(1.0 \%)$. This is also quite telling as it expresses a complete detachment to images with informative, political or social change purposes. 
We could say that consuming images via mobile phones seems an almost unpolitical activity and this only reinforces the notion of strengthening bonds of friendship and aspects of daily life.

As for what is done with photos viewed on mobile phones, respondents give "sharing with friends" (36\%) and "saving them to a device (35\%) as activies of greatest relevance". Here, what calls our attention is the fact that if photos are well-liked, our respondees will save them to the device and they will also share them with friends. This represents a type of hybrid activity, which sets a position between the kodaker and the snaper.

\section{Socialization}

In this section, we gather results related to photographic socialization. This includes which types of photos the young people are sharing, if these photos have been edited or not, if the edits are intended to be artistic, by which means and with what frequency they are taken, reasons for sharing these photos and which social networks are being used most in socializing photographs.

Here we see that $92.4 \%$ of respondees share their photos. $82.9 \%$ do so through a social network, $10 \%$ do so through uploading photos to a photography blog or profile, a mere $5 \%$ report to simply looking at photos on celphone screen with friends and family and just $1.1 \%$ say they actually print these photos. The most used social network for socializing photos is Instagram (51\%), followed by Facebook (35\%) and Twitter (5\%). This shows a notable increase in the use of a social network for socializing photos along with a very meaningful change in the use of Instagram in light of our previous study in which Facebook was the forerunner, being used by $79.7 \%$ of our sample (Bañuelos, 2011).

The most shared types of photos deal with "friends" (63\%), "landscapes" (58\%), "travel" (53\%) and "self portraits" (46\%). The least shared are of "festivities" (29\%), "family" (29\%) and "pets" (26\%). As can be appreciated here, the majority of photos shared belong to the private realm; however, as in our previous study, "friends" remains the most shared category (Bañuelos, 2011).

The most frequent reason given for sharing a photo on a social network is "to make an album" (34.4\%). This is followed by "to publish my work as a photographer" (24.4\%), and finally "to secure my relationship with friends" (22.2\%). This result contrasts greatly with our prior study (Bañuelos, 2011) where the main reason for sharing a photo was simply "to share with friends" (91\%). Added to this is another quite pronounced piece of data: $73 \%$ of these shared photos have been previously edited and $67 \%$ of young people report doing so with "artistic intention".

In terms of frequency of photo sharing on a social network, greatest frequency is reported as "a few hours afterward" (43.3\%), followed by "immediately after taking it" (18.8\%), and "a day after taking it" (15.5\%). This means that $77.6 \%$ of young people share photos within one day of taking them, and this represents a significant departure from our previous study (Bañuelos, 2011), in which 53.4\% reported sharing their photos "a couple of days afterward".

$60.2 \%$ of the sample has a personal homepage on a social network related to photography. Instagram is the most used network (65.1\%), followed by Tumblr (12.1\%), Flickr (6\%) and Pinterest (4.5\%). On balance, it is of great significance that $87.7 \%$ of our sample have a profile they use for uploading photos in a photography-dedicated social network.

A vast majority report to adding a commentary to photos when uploading to a social network (84.9\%) and $60.2 \%$ report adding a commentary to photos received as well. Thus, the rate of social participation through written commentaries is notably high. 


\section{Privacy}

This section explores whether young people share photos of their private lives and which topics are published or not. We do find that $56.9 \%$ of our sample share photos of their private lives (family get-togethers, significant others, parties, photos of their homes and children in their lives).

Topics that the young people are most willing to share are "travel" (80.4\%), "fun times with my friends" $(61.9 \%)$ and "self portraits" $(60.8 \%)$. Topics reported to not be published in a social network are "me drinking" (84.6\%), "sex" (83.5\%) and "my friends in compromising situations" (78\%).

Despite the apparent care taken in the publication of "private" topics, the young people are indeed willing to publish travel, friends and self portraits. Their understanding of "private" seems to be limited to sexuality, drunkenness and what they consider to be "compromising" situations. It seems to be more about moral topics and how others perceive them than the actual act of publishing aspects of private life, as the young people are quite willing to publish aspects of daily life such as "my significant other" (52.1\%), "me at a party" (53.2\%), and "my family" (47.8\%).

\section{Copyright}

Here we explore what the young people actually know about copyright issues. We also examine if they read the contracts of profiles they use in social networks and if they know which rights they are actually foregoing when publishing a photo in a network.

Our findings show that $83.8 \%$ do not read the contract when creating a profile on a social network. $64.5 \%$ report to being unaware of copyright regulations in the social network they use. In addition, $55.9 \%$ say they do not know which rights they yield or lose when uploading a photo to a social network.

$46.2 \%$ of the sample believe they lose "intellectual property" of their photos when uploading to a social network. 34.4\% affirm that they "yield their personal data", and $33.3 \%$ state that they surrender "patrimonial rights" to their photos. $20.4 \%$ believe they lose "the possibility of getting their images back", $19.3 \%$ affirm that they "do not surrender any rights" and $13.9 \%$ state that "all rights are surrendered". As can be appreciated here, there seems to be a great information gap and sense of apathy toward the notion of losing one's rights when uploading a photo to a social network and the need to actually read contracts.

There is a notably high rate of students who do not read the contracts and believe that "intellectual property" can be surrendered, and this is thought to be inalienable.

\section{Discussion}

The results of this study reveal that the Mexican young people in our sample have digital and technological competencies that bring them closer to "snaprs", yet they maintain the cultural photographic practices in keeping with "kodak" culture.

This is to say that on the one hand, these young people possess full technological architecture, smartphones, Internet access, computers and social networks. In addition, they take photos with great frequency and share them in a network almost immediately. On the other hand, however, these young people still save their photos on a drive. They do not simply leave them up on the web, and the topics most photographed and shared are within a private sphere focused on friends, travel and landscapes. This reinforces the affective ties that typically belong to "kodak" culture. 
As such, we may affirm that the sample of Mexican university students in the study at hand show a hybrid photographic culture with greater tendencies toward aspects of the "snapr" culture and somewhat less inclination toward "kodak" culture.

\section{Production}

Instagram has become the most important social network for sharing photos and has surpassed Facebook. Its appearance is very significant as it represents a paradigm shift in production, retouch or editing and sharing photographs via mobile phone.

A great majority of the students in our sample use IPhones and pay an average of 40 dollars a month, which indicates that there is a substantial economic investment in a Smartphone. This is related to camera quality and the fact that the students perceive it as a device of great relevance in their own photographic production.

Morever, we can find two significant tendencies here. The vast majority of the young people upload their photos on a social network to share their experiences and in order to create an album in a network specialized in photography. As well, the great majority are interested in editing and retouching photos before uploading them, making comments and conferring artistic value to them. This is a very clear display of "snapr" practice.

\section{Consumption}

Consumption is largely based on friends, famous people and landscapes. Photos are viewed mostly through Instagram and anywhere from 15 minutes to one hour is spent daily on this activity. Despite this, the networks which specialize in photography such as Flickr or 500pixels are used very infrequently. This denotes an inclination toward "snapr" culture while still being quite removed from specialized practices in professional photography.

As has been mentioned, what calls our attention is the fact that coveted photos are saved in celphone memory. This practice likens it toward the "kodak" culture where saving photos was deemed a necessity. Photograhers from the "snapr" culture, however, typically save all their shots in a network or in the cloud.

There also appears to be an almost complete detachment in consuming and photographing topics with social, political or civil movement nature. This indicates a strong-rooted "kodak" culture and an ideological stance of apathy when it comes to using the mobile camera and social networks for political objectives.

\section{Socialization}

The young people demonstrate high-level technological competencies when using a camera and sharing photographs through a social network. The vast majority share their snapshots in a social network and with great frequency. However, socialization continues to be carried out with friends and has to do with toipcs related to private life. We see this as a hybrid practice which lies between the "snaprs" and the "kodakrs".

There are other signs of this "snapr" tendency. There is a strong motivation to create some type of online photo album, the majority of students have created a profile dedicated to photography in a social network and most students make comments to photos they both consume and share.

\section{Privacy}

In terms of their dealing with issues of privacy, the students in our sample exhibit "snapr" culture as they are willing to publish a great array of topics related to family life, friends, significant others, trips and festivities. 
Nevertheless, topics related with sexuality and morally compromising situations continue to represent a moral barrier to their publication, and this finding is similar to our previous study (Bañuelos, 2011).

On balance, we may affirm that the young people exhibit "snapr" culture when it comes to privacy, yet at same time they uphold moral limitations in terms of publishing about sexuality.

\section{Copyright}

The young people in our sample clearly show "kodak" culture when it comes to copyright issues, displaying little care for the terms of contracts they sign when creating a profile in their social network of choice.

It is alarming that these young people who have access to a wide digital architecture are still so unaware of issues of copyright and privacy as outlined in social network contracts, particularly for those pertaining to rights of published photographs.

\section{Conclusions}

This study reveals a clear tendency in acquiring "snapr" rather than "kodak" culture (Miller \& Edwards, 2007) among young people. This inclination is largely based on technological competencies and practices of production, consumption and socialization together with the possibilities offered by mobile devices with Internet access such as real-time sharing of photos, editing, making profiles, albums and commentaries.

Nevertheless, we do find the persistence of "kodak" culture practices, which are largely based on topics related to the reinforcement of private life and friendships together with a nearly non-existent interest in other topics such as social or political life.

We also find a "kodak" culture in terms of copyright and conditions of social network uses via smartphones among the young people. This shows little knowledge of copyright issues in networks and a general lack of interest in reading contracts.

For some aspects, it can be affirmed that there are hybrid practices between "snapr" and "kodak" cultures. There is near-realtime sharing of photos, but these snapshots are focused on areas of private life. Also, comments are made and well-liked photos are shared on networks, but photos are also still being saved to celphone memory.

The production, consumption, socialization and copyright practices revealed in the work at hand denote that despite their access to a broad digital architecture and background in topics of image, communication and photography, the students in our sample present strong "kodak" type cultural ties. However, compared to our 2010 work, our students show some important signs of slowly but steadily heading toward a "snapr" culture.

Challenges for future studies in Mexico may include understanding photographic practices in mobile devices among less favoured populations in terms of access to digital architecture, devices and connectivity to social networks.

\section{References}

AMIPCI. (2015). 11 Estudio sobre los hábitos de los usuarios de Internet en México 2015 (11th study on the habits of Internet users in Mexico 2015). Retrieved September 24, 2015, from https://www.amipci.org.mx/es/noticiasx/2241-alcanza-internet-el-51-de-penetracion-entre-los-usuarios-potenciales-de-mexic o-amipci

Araya, D., Breindl, Y., \& Houghton, T. (2011). Nexus: New intersections in Internet research. New York: Peter Land Publishing, Inc. 
Bañuelos, J. (2011). Photography 2.0: Competences and cultural practices. Retrieved from http://www.razonypalabra.org.mx/varia/77_1A\%20PARTE/00_Banuelos_V77.pdf ISSN 1605-4806

Castells, M. (2006). La Sociedad Red. La era de la Información, economía, sociedad y cultura (Network Society: The information age, economy, society and culture). Madrid: Alianza Editorial.

Castells, M. (2007). Comunicación Móvil y Sociedad (Mobile communication and society). Madrid: Ariel.

Castells, M. (2009). Comunicación y Poder (Communication and power). Madrid: Alianza.

Castells, M. (2011). Democracy in the age of the Internet. Transfer: Jornal of contemporary culture, 6, 96-103.

Counts, S., \& Fellheimer, E. (2004). Supporting social presence through lightweight photo sharing on and off the desktop. Proceedings of the SIGCHI conference on Human factors in computing systems (pp. 599-606). ACM.

Chalfen, R. (1987). Snapshot versions of life. Bowling Green, Ohio: Bowling Green State University Popular Press.

David, G. (2014). The selfie research network. Retrieved November 15, 2015, from http://webcache.googleusercontent.com/search?q=cache:gCttAVV_EdQJ:www.selfieresearchers.com/wp-content/uploads/20 14/09/Selfie-grounding-bibliography-.docx $+\& \mathrm{~cd}=6 \& \mathrm{hl}=\mathrm{es}-419 \& \mathrm{ct}=\mathrm{clnk} \& \mathrm{gl}=\mathrm{mx}$

Hand, M. (2012). Ubiquitous Photography. Cambridge: Polity Press.

Hjorth, L. (2007). Snapshots of almost contact: The rise of camera phone practices and a case study of Seoul, Korea. Continuum: Journal of Media and Cultural Studies, 21(2), 227-38.

Hjorth, L. (2009). Photo Shopping: A snapshot on camera phone practices. Knowledge, Technology \& Policy Journal, 22(3), 157-159

Hjorth, L. (2010). Photoshifting: Art practice, camera phones and social media. Photofile, Issue 89.

LSE. (2013). Mobile visual references. Retrieved September 29, 2015, from http://www.lse.ac.uk/media@1se/WhosWho/AcademicStaff/LeslieHaddon/MobVisRefs.aspx

Manovich, L. (2009). Cultural analytics: Visualizing cultural patterns in the era of "More Media". DOMUS.

Manovich, L. (2012). Media visualization: Visual techniques for exploring large media collections. In K. Gates (Ed.), Media Studies Futures. Oxford: Blackwell.

Manovich, L. (2013). The Algorithms of our lives. Retrieved from http://chronicle.com/article/The-Algorithms-of-OurLives/143557/

Miller, A., \& Edwards, K. (2007). Give and take: A study of consumer photo-sharing culture and practice. Retrieved April 15, 2010, from http://portal.acm.org/citation.cfm?id=1240682

Miller-Ott, A. E., Kelly, L., \& Duran, R. L. (2012). The effects of cell phone usage rules on satisfaction in romantic relationships. Communication Quarterly, 60(1), 17-34.

Nov, O., Naaman, M., \& Ye, C. (2008). Community photo sharing: Motivational and structural antecedents. Retrieved March 15, 2010, from http://www.aaai.org/ocs/index.php/ICWSM/09/paper/download/206/426

Nov, O., Naaman, M., \& Ye, C. (2010). Analysis of participation in an online photo-sharing community: A multidimensional perspective. Journal of the American Society for Information Science and Technology (3), 555-566.

Palfrey, J., \& Gasser, U. (2008). Born digital: Understanding the first generation of digital natives. New York: Basic Books.

Prensky, M. (2001). Digital natives, digital immigrants. Retrieved from http://www.marcprensky.com/writing/Prensky\%20-\%20Digital\%20Natives,\%20Digital\%20Immigrants\%20-\%20Part1.pdf

Sarvas, R., \& Frohlich, D. (2011). From snapshots to social media-The changing picture of domestic photography. New York: Springer London Dordrech.

Thompson, J. (2005). The new visibility. Retrieved March 10, 2010, from http://tcs.sagepub.com/cgi/content/abstract/22/6/31

Van Dijck, J. (2008). Digital photography: Communications, identity, memory. Visual Communication, Visual Communication, $7(1), 57-76$.

Van House, N., \& Davis, M. (2005). The social life of cameraphone images. Retrieved from http://garage.sims.berkeley.edu/pub.cfm

Van House, N., Davis, M., Ames, M., Finn, M., \& Viswanathan, V. (2005). The uses of personal networked digital imaging: An empirical study of cameraphone photos and sharing. Portland, Oregon: ACM Press.

Yan, S. (2015). Encyclopedia of mobile phone behavior. Retrieved from $\mathrm{https}$ //books.google.com.mx/books?id=bIkfCgAAQBAJ\&printsec=frontcover-v=onepage \&q\&f=false 